\title{
A Protocol to Follow-up with Students in Large-enrollment Courses
}

\section{Mr. Matías Alonso Piña, Pontificia Universidad Católica de Chile}

Engineering student from Chile.

\section{Miss Isabel Hilliger P.E., Pontificia Universidad Católica de Chile}

Isabel Hilliger is the Associate Director for Assessment and Evaluation at the Engineering Education Division in Pontificia Universidad Católica de Chile (UC). Isabel received a BEng and PhD in Engineering Sciences from UC, and an MA in Policy Organization, and Leadership Studies from Stanford Graduate School of Education. Her research theme is the use of methodologies and analytical tools for continuous curriculum improvement in Higher Education. She has created qualitative and quantitative instruments for outcome assessment in enginering education. She has also evaluated policy efforts towards engineering diversity and undergraduate research.

\section{Jorge A. Baier, Pontificia Universidad Católica de Chile}

He is an associate professor in the Computer Science Department and Associate Dean for Engineering Education at the Engineering School in Pontificia Universidad Católica de Chile. Jorge holds a PhD in Computer Science from the University of Toronto in Canada and a Master's Degree in Engineering Sciences from Pontificia Universidad Católica de Chile. His research focuses on areas of automated reasoning in Artificial Intelligence; specifically, automated planning, search and knowledge representation. $\mathrm{He}$ is also interested in the development of teaching approaches and systems that promote the wellbeing of students.

\section{Miss Constanza Melian, Pontificia Universidad Católica de Chilev}

Constanza Melian is Assessment and Evaluation Coordinator for Division of Engineering Education at Pontificia Universidad Católica de Chile. Constanza is sociologist, interested in issues of education, social inequality, poverty and gender gaps. Methodologically his interests and work is in survey design, construction of quantitative instruments, statistical data analysis and evaluation of social programs.

\section{Dr. Cristian Ruz, Pontificia Universidad Católica de Chile}

Mr. Tomás Andrés González, Pontificia Universidad Católica de Chile 


\section{A Protocol to Follow up Students in Large-Enrollment Courses}

\section{Introduction}

In response to the COVID-19 health crisis, two thirds of higher education institutions quickly moved to online education [1]. As a result, students faced unexpected difficulties, such as lack of a good study environment, which affected their wellbeing [1]. Aware of those additional difficulties, some institutions promoted a flexible approach, suggesting teachers to increase communication with their students and make the necessary modifications to course evaluations and deadlines [2], [3]. Engineering students perceive that higher workload affects their wellbeing [4], which, in turn, is a key component to their engagement [4].

To approach teaching in a flexible manner, instructors need to make themselves aware of the needs of their students. In courses with a large enrollment ( $\sim 400$ students) [5], henceforth referred to as massive courses, where student-instructor communication is usually burdened, gaining such an awareness is particularly difficult. Remote online settings, unfortunately, exacerbate social isolation [6].

This paper describes a case of study in which we describe and evaluate a wellbeing protocol designed to actively engage in communication with students either with lower-than-average academic performance, with missing/late assignments, or with personal issues unrelated to the course that need orientation. Using soothing language and attempting to be as empathetic as possible, a member of the teaching staff, henceforth referred to as the wellbeing teaching assistant (TA), contacts students, attempts to establish the causes of low academic performance and proposes specific actions in response to students' needs. The protocol was implemented in the Advanced Programming course, during the second term of 2020, at the School of Engineering at Pontificia Universidad Católica de Chile (UC-Eng). The course had an enrollment of 578 students and had been identified by the UC-Eng as one that demands higher-than-average time from students. To evaluate the student's perceptions of our approach, we collect data from several sources, including an online survey and group interviews, specifically designed to evaluate the perceptions of this approach. We conclude that our wellbeing protocol is beneficial for students and that students recommend its implementation in other courses with high enrollment.

The wellbeing of students has been identified as central to student engagement [7]. A component that distinguishes our protocol from other approaches to wellbeing described in the literature, such as mentoring and peer-to-peer tutoring approaches (e.g., [4]), is that it engages in active, personalized communication with students. Furthermore, the wellbeing TA, as currently conceived, is a member of the teaching staff, and thus fully aware of the course workload and challenges with direct communication with the course instructor.

\section{The Protocol}

Now we describe the protocol executed by the wellbeing TA. At the beginning of the course, we obtain consent for the students, informing them that their academic performance will be monitored during the term as part of the wellbeing program of the course. After the first two course evaluations, the grades of the students are input into a pretrained naive Bayes model designed to predict the likelihood of failing the course. We used this technique since it had been shown to have good prediction results in a similar setting [8]. Every student selected is 
sent an email similar to the one shown in Figure 1. After receiving a response from the student, communication is continued using the most appropriate means (e.g., email, video call, text messaging). Based on this exchange, the TA classifies the causes of the low academic performance and offers help. The categories and actions taken are shown in Table 1. An emphasis is placed on flexibility and offering personalized academic help. Flexibility refers to offering personalized deadlines depending on the severity of the situations the student is facing. Personalized academic help refers to determining which contents of the course need to be reinforced and suggesting appropriate actions, which range from reviewing written material to one or more help interviews. In case of mental health issues, especially if these are not being treated, the student is put in contact with the school's academic advisors who are psychologists who provide academic counseling. Academic advisors may forward the student to the University's health services and contact the instructors to help them tailor the course to the needs of the student, if appropriate. Students that directly address the wellbeing TA or that fail to submit an assessment at any moment of the semester are also sent the same email of Figure 1 and go through the same protocol.

\section{Methods}

The mixed methods study used a convergent parallel design to inform the protocol for following up on students in massive courses, complementing quantitative and qualitative findings [9]. In this study, the research problem consists of exploring students' expectations regarding their wellbeing and their relationship with teaching staff members in massive courses, along with identifying perceived benefits from the implementation of the protocol described in section 2, in order to follow up on students' wellbeing course in an advanced programming course at a Latin American university during the second semester of 2020. In that academic period, 4 course sections were offered in an online format to 578 students.

In order to collect quantitative data, we conducted an online survey by the end of November of 2020, which was voluntarily answered by a convenience sample of $39.5 \%$ of the students enrolled in the Advanced Programming course (228 out of the 578). A 10-point scale was used to measure how recommendable this type of protocol was in other courses, and open-ended questions were used to ask students about their expectations regarding the wellbeing TA and his role to follow up on students.

In order to collect qualitative data, we conducted two group semi-structured interviews with a total of 7 students ( 4 students in the first interview and 3 in the second interview), 6 of which had also answered the survey. The interview questions were based on an existing mixed methods study to explore students' perceptions of interventions to improve their well-being [4]. The interviews were conducted by a moderator and a research assistant, who obtained notes and audio files under the informed consent of participants. These audio files were transcribed verbatim, and a thematic analysis was conducted according to the phases described by Nowell et al. [4]. Quotes were also extracted to exemplify the codes that emerged from this thematic analysis. 


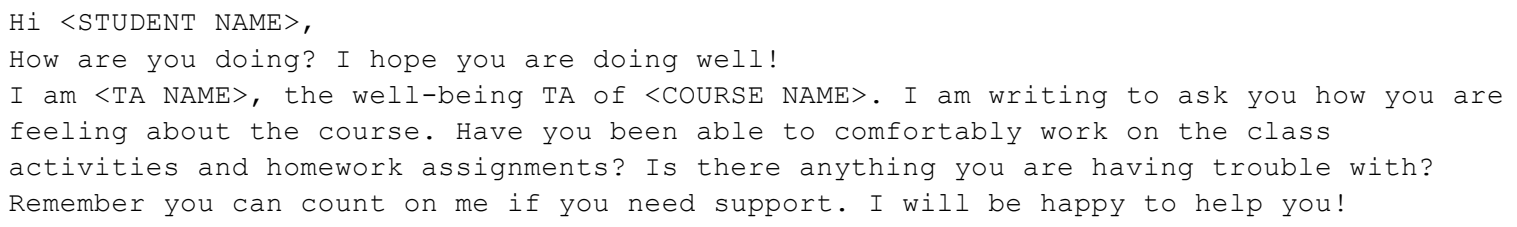

Figure 1: Email sent by the wellbeing TA to the student

Table 1: Causes of low academic performance and actions taken by the TA

\begin{tabular}{|l|l|}
\hline Cause & Possible Actions \\
\hline Isolated/non-recurring situation & No further actions are taken \\
\hline $\begin{array}{l}\text { High time demand at the moment due to non-academic } \\
\text { compulsory activities (i.e., extra-curricular activities, care } \\
\text { taking of a child) }\end{array}$ & $\begin{array}{l}\text { Offer personalized academic help and/or flexibility } \\
\text { (i.e., modify deadlines). }\end{array}$ \\
\hline $\begin{array}{l}\text { Personal issues (i.e., health issues with the students of family } \\
\text { members) or anxiety associated with the course (e.g., because } \\
\text { the student failed this course in the past) }\end{array}$ & $\begin{array}{l}\text { Inform/connect the student with University Health } \\
\text { services and/or academic advisors, if needed. Offer } \\
\text { personalized academic help and/or flexibility (i.e., } \\
\text { deadline modification). }\end{array}$ \\
\hline Difficulty understanding the material of the course & Offer personalized academic help \\
\hline Connectivity issues / low-quality study environment & Flexibility (i.e., modify deadlines). \\
\hline
\end{tabular}

\section{Results}

Table 2 summarizes the main findings of this study. Columns correspond to the information obtained from the survey (center column) and the group interviews (right column) that was used to extrapolate the findings. To obtain each finding, we triangulated results obtained from the student survey and the group interviews.

A main finding is that students expressed that the wellbeing TA was beneficial in multiple ways. This was made clear in the student survey, where one of the questions was: "According to your experience with the wellbeing TA, how much would you recommend the presence of a wellbeing TA in university courses?". With a scale from 1 to 10 , the average score was 8.934 , and $86.6 \%$ of the students provided an answer greater than 7 (168 out of 196), which was considered to be positive. Complementing these results, 6 of the 7 participants of the group interviews mentioned they obtained one or multiple benefits from contacting the wellbeing TA, while the seventh participant did not answer this question. Regarding these benefits, the most common one was feeling accompanied during the semester, which was mentioned by all students who answered the question during both group interviews:

"...it was a great relief to have someone who cared about my wellbeing in the course and that really listened to me and tried to do something for me, even if he wouldn't have been able to do anything, the simple fact of him trying was a really huge relief."

The second finding indicates that the students recommend implementing a wellbeing TA in other courses of the university, specifically in courses with a large number of students enrolled. This is shown in the results of the survey, where $97.94 \%$ of the surveyed students 
Table 2: Main findings obtained from triangulating results obtained from interviews and surveys

\begin{tabular}{|c|c|c|}
\hline Findings & Survey & Group interviews \\
\hline $\begin{array}{l}\text { 1. Students consider that the } \\
\text { presence of the wellbeing } \\
\text { TA was beneficial. }\end{array}$ & $\begin{array}{l}\text { When asked about how advisable was } \\
\text { the presence of a wellbeing TA in a } \\
\text { course, on a scale from } 1 \text { to } 10,86.6 \% \\
\text { of the students answered with a score } \\
\text { greater than } 7 \text { ( } 168 \text { out of } 196) \text {. }\end{array}$ & $\begin{array}{l}85.7 \% \text { of the participants mentioned one } \\
\text { or multiple benefits from contacting the } \\
\text { wellbeing TA ( } 6 \text { out of } 7 \text { ), ranging from } \\
\text { calendar flexibility to a feeling of } \\
\text { accompaniment. }\end{array}$ \\
\hline $\begin{array}{l}\text { 2. Students recommend the } \\
\text { incorporation of a wellbeing } \\
\text { TA in other courses, } \\
\text { particularly in those with a } \\
\text { large number of students. }\end{array}$ & $\begin{array}{l}96.94 \% \text { of the surveyed students } \\
\text { expressed that they would like a } \\
\text { wellbeing TA being incorporated in } \\
\text { other courses ( } 190 \text { out of } 196) \text {, mainly } \\
\text { first year and massive courses. }\end{array}$ & $\begin{array}{l}85.7 \% \text { of the participants mentioned that a } \\
\text { wellbeing TA would be especially } \\
\text { beneficial in massive courses ( } 6 \text { out of } 7 \text { ). }\end{array}$ \\
\hline $\begin{array}{l}\text { 3. The main reasons students } \\
\text { contacted the wellbeing TA } \\
\text { were personal matters and } \\
\text { mental health issues. }\end{array}$ & $\begin{array}{l}23.2 \% \text { of the surveyed students } \\
\text { mentioned in an open question that they } \\
\text { expected the wellbeing TA to help } \\
\text { students with personal matters or } \\
\text { mental health issues ( } 45 \text { out of } 228 \text { ). }\end{array}$ & $\begin{array}{l}71.4 \% \text { of the participants mentioned } \\
\text { personal matters as the reason for } \\
\text { contacting the wellbeing TA ( } 5 \text { out of } 7) \text {. } \\
\text { It was the most repeated contact motive. }\end{array}$ \\
\hline
\end{tabular}

expressed that they would like a wellbeing TA being implemented in other courses, as well as in the answers given by the participants of the group interviews, where 6 people mentioned that a wellbeing TA would be especially helpful in massive courses.

Finally, the third finding of this study shows that the main reasons students contacted the wellbeing TA were personal matters and mental health issues. This was first suggested by the survey, where $23.2 \%$ of the participants mentioned that they would expect a wellbeing TA to be able to help them with these issues, and was later confirmed by the interviews, where personal matters were the most common contact reason mentioned by the students:

'...I remember that I was having issues because of reasons that I didn't consider to be academic, for example, my family had relatives going through serious health issues due to the coronavirus (...) and I asked the wellbeing TA for help (...) and truly, the way he treated me, the way he helped me, the way in which he guided me, was a very human, and I liked that very much...'

\section{Discussion}

The results of this study suggest that scaling our approach to a School level would bring important benefits to students. However, there are questions that remain to be answered. Further studies are needed to evaluate what resources are required, and notably what type of training is needed for wellbeing TAs. Moreover, there was a high work overload perceived by the wellbeing TA, who is expected to answer requests in a timely manner. This could be addressed by automating some of their tasks. Thus, further research should explore the design and implementation of automated tools to assist them in their duties.

This mixed-methods study was conducted in a specific geographical setting. Thus, one of its limitations is that its findings may not extrapolate to engineering schools in other countries. 


\section{Acknowledgements}

We are grateful to Sebastián Barriga and Joaquín Ossandón, for their comments on an earlier draft of this paper. This work was supported by CORFO under grant number 14EN12-26862.

\section{References}

[1] IAU, The Impact of Covid-19 on Higher Education around the World. 2020.

[2] J. J. B. Joaquin, H. T. Biana, and M. A. Dacela, "The Philippine Higher Education Sector in the Time of COVID-19," Front. Educ., vol. 5, no. October, pp. 1-6, 2020, doi: $10.3389 /$ feduc. 2020.576371.

[3] T. Khraishi, "Teaching in the COVID-19 Era: Personal Reflections, Student Surveys and Pre-COVID Comparative Data," Open J. Soc. Sci., vol. 09, no. 02, pp. 39-53, 2021, doi: 10.4236/jss.2021.92003.

[4] D. Chadha et al., "Are the kids alright? Exploring students' experiences of support mechanisms to enhance wellbeing on an engineering programme in the UK," Eur. $J$. Eng. Educ., vol. 0, no. 0, pp. 1-16, 2020, doi: 10.1080/03043797.2020.1835828.

[5] M. Schar, A. Harris, R. J. Witt, R. Rice, and S. Sheppard, "Connecting for success; The impact of student-to-other closeness on performance in large-scale engineering classes," ASEE Annual Conf. Expo. Conf. Proc., vol. 2016-June, 2016, doi: $10.18260 /$ p.26568.

[6] J. Gillett-Swan, "The Challenges of Online Learning: Supporting and Engaging the Isolated Learner," J. Learn. Des., vol. 10, no. 1, p. 20, 2017, doi: 10.5204/jld.v9i3.293.

[7] E. R. Kahu and K. Nelson, "Student engagement in the educational interface: understanding the mechanisms of student success," High. Educ. Res. Dev., vol. 37, no. 1, pp. 58-71, 2018, doi: 10.1080/07294360.2017.1344197.

[8] W. F. W. Yaacob, S. A. M. Nasir, W. F. W. Yaacob, and N. M. Sobri, "Supervised data mining approach for predicting student performance," Indones. J. Electr. Eng. Comput. Sci., vol. 16, no. 3, pp. 1584-1592, 2019, doi: 10.11591/ijeecs.v16.i3.pp1584-1592.

[9] J. W. Creswell, Educational research: Planning, conducting, and evaluating quantitative and qualitative research, 4th Edition. Boston, Massachusetts: Pearson Education, Inc., 2012. 